\title{
EPIDEMIOLOGICAL INFORMATION FROM ACTIVE AND PASSIVE PYOCINE TYPING OF PSEUDOMONAS AERU- GINOSA
}

\author{
F. R. Falkiner and C. T. Keane \\ Department of Microbiology, Federated Dublin Voluntary Hospitals, \\ Adelaide Hospital, Peter Street, Dublin 8
}

\section{Plate XXXI}

PSEUDOMONAS AERUGINOSA is an important cause of infection in hospital patients (Kominos, Copeland and Grosiak, 1972; Liljedahl et al., 1972; AlDujaili and Harris, 1975; Thomas et al., 1975) and is difficult to control owing to its resistance to many antibiotics (Jacoby, 1974; Eykyn and Phillips, 1975; Korfhagen, Loper and Ferrel, 1975).

Various methods of typing have been used in epidemiological investigations. Serological typing, based on the $\mathrm{O}$ somatic antigens, is easy to perform and the results are generally reliable (Parker, 1972). Antisera are available commercially (Al-Dujaili and Harris, 1974) and are convenient to use, but there is no information on their potency. A disadvantage is that certain serological types predominate.

Bacteriophage typing requires facilities that may not be available in all routine diagnostic laboratories; although a variety of typing patterns occur, reproducibility is less satisfactory than in staphylococcus phage typing. The combined use of phage typing and serological typing may be of value in subdividing the common serotypes (Parker, 1972).

Pyocine typing may be accomplished in two ways, namely "active" and "passive". "Active" pyocine typing depends on the pattern of growth inhibition produced by the pyocines of the strain being typed on a set of indicator strains of P. aeruginosa. "Passive" typing depends on the susceptibility of the strain being typed to the pyocines produced by a set of $P$. aeruginosa strains chosen for the purpose. The most widely used active method is that of Gillies and Govan (1965) and Govan and Gillies (1969). This method has been used extensively in epidemiological studies (Tinne et al., 1967; Henderson, Maclaurin and Scott, 1969), though sometimes with modifications (Tagg and Mushin, 1971). It is simple to perform, but certain strains are poor pyocine producers, and 2 days are required for the test, although results may be obtained more rapidly when mitomycin $\mathrm{C}$ induction is employed (Tripathy and Chadwick, 1971). Osman (1965) and Farmer and Herman (1969) have described methods of passive pyocine typing. However, some of the pyocine preparations used contained bacteriophage. Rampling and Whitby (1972) described a method of preparing lysates, free of contaminating phage particles. A preliminary report on the use of these lysates was promising (Rampling, Whitby and Wildy, 1975).

Rampling et al. (1975) made use of the passive method in epidemiological investigations. We report here our experience with both active and passive methods of pyocine typing in epidemiological investigations over a 3-year period.

Received 30 June 1976; revised version accepted 4 May 1977.

J. MED. MICRODIOL.-VOL. 10 (1977) 
$2 \mathrm{ml}$ of emulsion were injected into the other hind leg. The animals were bled out after a further week. When required, the appropriate neutralising antiserum $(0.2 \mathrm{ml})$ was added to the uv-treated lysates and incubated at $37^{\circ} \mathrm{C}$ for $30 \mathrm{~min}$. The treated lysates were diluted 1 in 5 in TSB and stored at $4^{\circ} \mathrm{C}$ for up to 6 weeks. The efficacy of neutralising antiserum was established each time it was used.

The strain to be typed was grown overnight at $32^{\circ} \mathrm{C}$ in peptone water. One drop $(0.02 \mathrm{ml})$ of this culture was mixed with $5 \mathrm{ml}$ of molten $0.7 \%$ Oxoid Agar No. 1 at $45-50^{\circ} \mathrm{C}$. This was overlaid on two nutrient-agar plates and these were left to dry. The pyocine-containing lysates were spotted on these with a carousel-type phage-typing machine (Biddulph and Co., Manchester, Ltd). The plates were dried and incubated at $30^{\circ} \mathrm{C}$ overnight.

Inhibition reactions were scored ++ (clear zone), + and \pm (less clear zones) and $( \pm)$ (very faint zone). Repeated observations on individual strains showed that the very faint reactions occurred irregularly and they were therefore disregarded in interpreting the results. The intensity of reaction was partly dependent on the density of the inoculum. A suitable "lawn" is shown in the figure.

In interpreting the results, we used the criteria of Rampling et al. (1975). Any two strains with three or more differences in their pyocine-sensitivity patterns were regarded as distinct. Strains with only one or two such differences were regarded as indistinguishable.

\section{Assay of pyocine preparations}

Potency of pyocine preparations is more difficult to estimate than that of phage preparations because the end-point is less easy to define, and the lysates may contain more than one pyocine. However, a modification of the method described by Paterson (1965) was used to assess pyocine activity (see table III). The crude lysates were assayed immediately after preparation and again after $1,3,6,12$ and 18 months' storage at $4^{\circ} \mathrm{C}$. The method was as follows.

The 12 strains recorded as the most sensitive indicators by Rampling et al. (1975) were seeded on nutrient agar plates in duplicate as for routine passive-pyocine typing. The lysates were uv-irradiated to inactivate phages and, if required, treated with the neutralising antisera. Six serial 10-fold dilutions of the treated lysates were prepared, with a fresh pipette for each dilution. A drop of each dilution was placed on plates seeded with the appropriate indicator strains, each lysate being titrated in duplicate. Pasteur pipettes delivering 30 drops per $\mathrm{ml}$ were used. The plates were dried and incubated at $30^{\circ} \mathrm{C}$ overnight.

The endpoint was taken as the dilution that gave a reaction graded + (see figure). This was chosen because a strong reaction was less dependent on interpretive error and inoculum size. It is perhaps analogous to the endpoint of a phage titration, in which the " routine test dilution" (that giving " nearly complete lysis") can be accurately determined (Blair and Williams, 1961).

\section{Tests for reproducibility of active and passive pyocine typing methods}

Many factors may affect the reproducibility of these procedures. They include the stability of test, producer and indicator strains, the stability of the pyocine preparations, and the nature of the growth conditions. To take account of as many of these variables as possible, three approaches were used. (1) On the same day, 10 colonies were picked from each of 10 epidemiologically unrelated strains of $P$. aeruginos $a$ and typed twice by the active method and twice by the passive method. (2) The same 10 strains were typed twice by the active method and twice by the passive method at intervals of 2-3 weeks over a period of 27 weeks. For the passive method, the same stock preparations of crude lysates were used over the 27-week period. These were uv-irradiated and diluted 1 in 5 on each occasion before use. (3) To assess consistency in the typing of strains isolated from individual patients, both typing techniques were applied to all isolates from 25 patients each of whom had contributed three or more cultures of $P$. aeruginosa. Each batch of strains typed included as controls the 12 sensitive strains described by Rampling et al. (1975). 


\section{RESULTS}

\section{Distribution of pyocine types}

Table I gives the results of active pyocine typing of the 839 strains of $P$. aeruginosa. Types 1 and 3 were the most common and accounted for just over $50 \%$ of all cultures. The subtyping of type- 1 strains is summarised in table II. A total of 42 isolates $(5 \%)$ could not be typed by the active method, whereas 73 of 1008 strains $(7 \cdot 24 \%)$ were untypable by the passive method. Of 726 strains tested by both methods, 35 were untypable by the passive method, 23 were untypable by the active method and nine were untypable by both methods.

TABLE I

Typing of 839 isolates of Pseudomonas aeruginosa by the active pyocine method

\begin{tabular}{c|cc}
\hline \multirow{2}{*}{ Type } & Number of isolates & Percentage \\
\cline { 2 - 3 } 1 & & \\
\cline { 2 - 3 } 2 & 272 & $32 \cdot 4$ \\
3 & 14 & $1 \cdot 7$ \\
5 & 149 & $17 \cdot 8$ \\
6 & 43 & $5 \cdot 1$ \\
8 & 27 & $3 \cdot 2$ \\
10 & 11 & $1 \cdot 3$ \\
22 & 16 & $1 \cdot 9$ \\
26 & 35 & $4 \cdot 2$ \\
Others* & 12 & $1 \cdot 4$ \\
UC & 61 & $7 \cdot 3$ \\
NT & 157 & $18 \cdot 7$ \\
& 42 & $5 \cdot 0$ \\
\hline
\end{tabular}

* Of 21 types, each accounted for less than $1 \%$ of the 839 strains.

$\mathrm{UC}=$ Unclassifiable, i.e., the inhibition patterns did not conform to those of the recognised types of Govan and Gillies (1969).

$\mathrm{NT}=$ Non-typable, i.e., gave no inhibition reactions.

TABLE II

Subtyping of 272 strains of the active pyocine type 1

\begin{tabular}{c|ccc}
\hline Type & Number of isolates & $\begin{array}{c}\text { Percentage } \\
\text { (of 272 type-1 } \\
\text { isolates) }\end{array}$ & $\begin{array}{c}\text { Percentage } \\
\text { (of 839 isolates } \\
\text { of any type) }\end{array}$ \\
\hline & & & \\
1a & 7 & $2 \cdot 6$ & $0 \cdot 8$ \\
1b & 23 & $8 \cdot 5$ & $2 \cdot 7$ \\
1c & 87 & $32 \cdot 0$ & $10 \cdot 4$ \\
1d & 44 & $16 \cdot 2$ & $5 \cdot 2$ \\
1e & 7 & $2 \cdot 6$ & $0 \cdot 8$ \\
1f & 3 & $1 \cdot 1$ & $0 \cdot 4$ \\
1g & 5 & $1 \cdot 8$ & $0 \cdot 6$ \\
1h & 57 & $21 \cdot 0$ & $6 \cdot 8$ \\
1UC & 39 & $14 \cdot 3$ & $4 \cdot 7$ \\
\hline
\end{tabular}

$1 \mathrm{UC}=$ Type 1 strains with subtyping patterns of inhibition other than those of the subtypes $a-h$ of Govan and Gillies (1969). 
ACTIVE AND PASSIVE PYOCINE TYPING
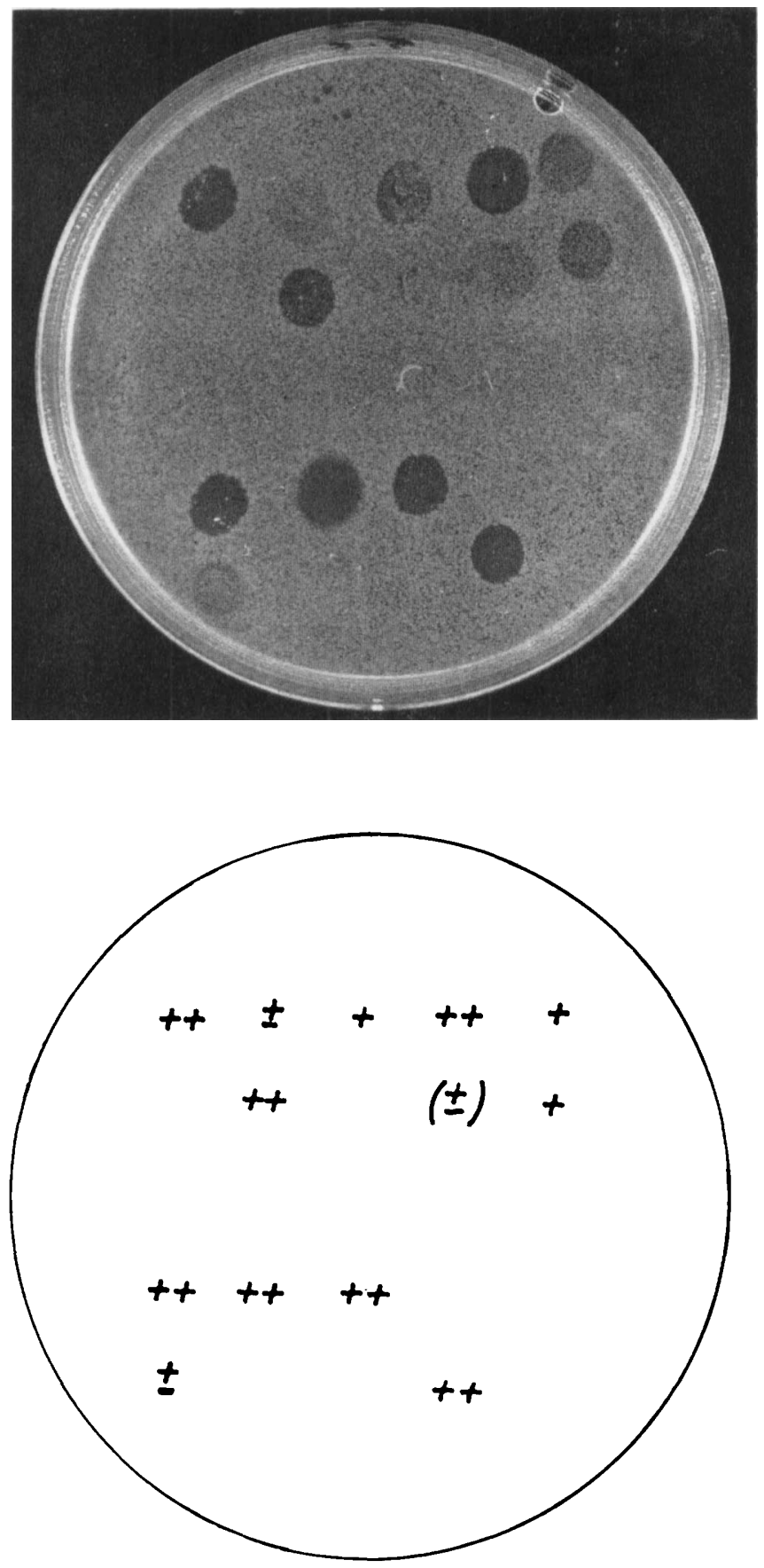

FIGURE.-The interpretation of passive pyocine typing of Pseudomonas aeruginosa. The four grades of reaction,,,+++ \pm and $( \pm)$, are defined under Materials and methods. The largest zone in the second row from the bottom is due to a small molecule " $\mathrm{S}$-type " pyocine. 
TABLE III

Repeated assays of 24 pyocine preparations over a period of 18 months

\begin{tabular}{|c|c|c|c|c|c|c|c|}
\hline \multirow{2}{*}{ Lysate number } & \multirow{2}{*}{$\begin{array}{l}\text { Indicator } \\
\text { strain }\end{array}$} & \multicolumn{6}{|c|}{$\begin{array}{l}\text { Relative potency* of lysates at the } \\
\text { stated times (months) after preparation }\end{array}$} \\
\hline & & 0 & 1 & 3 & 6 & 12 & 18 \\
\hline 1 & G1 & 4 & 4 & 4 & 4 & 4 & 3 \\
\hline 2 & G1 & 4 & 4 & 4 & 4 & 3 & 3 \\
\hline 3 & G1 & 4 & 4 & 3 & 3 & 3 & 2 \\
\hline 4 & $\begin{array}{l}\text { G1 } \\
\text { GE }\end{array}$ & $\begin{array}{l}5 \\
4\end{array}$ & $\begin{array}{l}4 \\
4\end{array}$ & $\begin{array}{l}4 \\
4\end{array}$ & $\begin{array}{l}4 \\
3\end{array}$ & $\begin{array}{l}4 \\
3\end{array}$ & $\begin{array}{l}3 \\
3\end{array}$ \\
\hline 5 & $\begin{array}{l}\text { G8 } \\
\text { GA } \\
\text { NIH26 }\end{array}$ & $\begin{array}{l}3 \\
3 \\
3\end{array}$ & $\begin{array}{l}3 \\
3 \\
2\end{array}$ & $\begin{array}{l}3 \\
3 \\
2\end{array}$ & $\begin{array}{l}2 \\
2 \\
1\end{array}$ & $\begin{array}{l}\frac{1}{2} \\
1\end{array}$ & $\begin{array}{l}0 \\
2 \\
1\end{array}$ \\
\hline 6 & $\begin{array}{l}\text { G1 } \\
\text { GE }\end{array}$ & $\begin{array}{l}4 \\
4\end{array}$ & $\begin{array}{l}1 \\
1\end{array}$ & $\begin{array}{l}1 \\
1\end{array}$ & $\begin{array}{l}\mathbf{0} \\
1\end{array}$ & $\begin{array}{l}0 \\
1\end{array}$ & $\begin{array}{l}0 \\
1\end{array}$ \\
\hline 7 & G1 & 3 & 2 & 2 & 2 & 2 & 1 \\
\hline 8 & $\begin{array}{l}\text { G8 } \\
\text { GC }\end{array}$ & $\begin{array}{l}3 \\
3\end{array}$ & $\begin{array}{l}3 \\
3\end{array}$ & $\frac{2}{2}$ & $\frac{2}{2}$ & $\begin{array}{l}2 \\
1\end{array}$ & $\begin{array}{l}<1 \\
<1\end{array}$ \\
\hline 9 & $\mathrm{G} 4$ & 5 & 5 & 4 & 4 & 3 & 3 \\
\hline 10 & $\begin{array}{l}\text { G3 } \\
\text { G7 }\end{array}$ & $\begin{array}{l}4 \\
4\end{array}$ & $\begin{array}{l}4 \\
3\end{array}$ & $\begin{array}{l}4 \\
2\end{array}$ & $\begin{array}{l}4 \\
2\end{array}$ & $\begin{array}{l}3 \\
1\end{array}$ & $\begin{array}{l}3 \\
1\end{array}$ \\
\hline 11 & G7 & 4 & 3 & 3 & 2 & 2 & 2 \\
\hline 12 & $\begin{array}{l}\text { G1 } \\
\text { QEB }\end{array}$ & $\begin{array}{l}4 \\
5\end{array}$ & $\begin{array}{l}4 \\
3\end{array}$ & $\begin{array}{l}4 \\
3\end{array}$ & 2 & $\frac{2}{2}$ & $\begin{array}{l}2 \\
0\end{array}$ \\
\hline 13 & NIH18 & 2 & 2 & 2 & 2 & 1 & 0 \\
\hline 14 & GE & 4 & 2 & 2 & 2 & 1 & 1 \\
\hline 15 & $\begin{array}{l}\text { G1 } \\
\text { GE }\end{array}$ & $\begin{array}{l}5 \\
2\end{array}$ & $\begin{array}{l}5 \\
2\end{array}$ & $\begin{array}{l}3 \\
1\end{array}$ & $\begin{array}{l}3 \\
1\end{array}$ & $\begin{array}{l}3 \\
1\end{array}$ & $\begin{array}{l}3 \\
0\end{array}$ \\
\hline 16 & $\begin{array}{l}\text { G1 } \\
\text { NIH18 }\end{array}$ & $\begin{array}{l}4 \\
3\end{array}$ & $\begin{array}{l}4 \\
3\end{array}$ & $\begin{array}{l}4 \\
2\end{array}$ & $\begin{array}{l}3 \\
2\end{array}$ & $\begin{array}{l}3 \\
1\end{array}$ & $\begin{array}{l}3 \\
0\end{array}$ \\
\hline 17 & GE & 4 & 2 & 2 & 1 & 1 & 1 \\
\hline 18 & GE & 3 & 2 & 2 & 2 & 2 & $<1$ \\
\hline 19 & G3 & 3 & 3 & 3 & 3 & 3 & 1 \\
\hline 20 & G8 & 5 & 4 & 4 & 4 & 4 & 1 \\
\hline 21 & G1 & 5 & 5 & 3 & 3 & 2 & 0 \\
\hline 22 & $\begin{array}{l}\text { GA } \\
\text { NIH26 }\end{array}$ & 2 & $\begin{array}{l}2 \\
3\end{array}$ & $\begin{array}{l}2 \\
3\end{array}$ & $\begin{array}{l}2 \\
3\end{array}$ & $\begin{array}{l}1 \\
1\end{array}$ & $\begin{array}{r}0 \\
<1\end{array}$ \\
\hline 23 & GA & 2 & 2 & 2 & 1 & 1 & 0 \\
\hline 24 & $\begin{array}{l}\text { G1 } \\
\text { GB }\end{array}$ & $\begin{array}{l}6 \\
4\end{array}$ & $\begin{array}{l}4 \\
4\end{array}$ & $\begin{array}{l}4 \\
2\end{array}$ & $\begin{array}{l}4 \\
2\end{array}$ & $\begin{array}{l}3 \\
2\end{array}$ & $<\frac{2}{1}$ \\
\hline
\end{tabular}

* $\log _{10}$ of reciprocal dilution of lysate preparation giving an inhibition reaction graded + against the indicator strains found by Rampling et al. (1975) to be the most sensitive. 


\section{Stability of pyocine preparations over 18 months}

The assay method was designed to correlate as closely as possible with the technique of passive typing. The results given in table III show that, with the exception of lysate no. 6, the pyocines retained activity against the mostsensitive indicator strains for 12 months. Surprisingly, lysate 17 prepared from the same producer strain as lysate 6 , but treated with neutralising antiserum, retained slightly higher activity over the 12 months. Similar treatment of the crude lysate, numbered and used as 6 , marginally improved its action against indicator strain GE. Activity of lysate 6 against some other indicators was less rapidly lost.

\section{Reliability and reproducibility of both typing methods}

Ten strains of $P$. aeruginosa were typed twice by the active method and twice by the passive method in 10 replicate experiments on the same day. The active typing results showed no variation. The passive typing results showed minor variations in the pyocine susceptibility patterns, but more than two strong differences in reaction-the requirement for distinguishing between two different isolates according to Rampling et al. (1975) - were never found.

Over the 27-week period in which reproducibility of typing was examined, there was no variation in the active typing results, but there was an apparent loss in the potency of some of the lysates used for passive typing (table III), particularly lysate 6 . There was a diminution in the strength of the inhibition reaction and in some cases a total loss of reaction (table IV) that was not reflected in the controls.

The typing results, in respect of strains isolated from 25 patients from whom three or more cultures were obtained, were compared. For the strains isolated from 16 patients, the two methods of pyocine typing were in full agreement.

\section{TABLE IV}

Variations in the passive pyocine-typing patterns observed when 10 strains were typed induplicate at intervals of 2-3 weeks for a period of 27 weeks

\begin{tabular}{|c|c|c|}
\hline $\begin{array}{c}\text { Strain } \\
\text { number }\end{array}$ & Initial typing pattern & Variations observed* \\
\hline $\begin{array}{l}138 \\
338 \\
460 \\
490 \\
636 \\
680 \\
690 \\
785 \\
818 \\
959\end{array}$ & $\begin{array}{l}4,5,9 \\
1,2,3,4,5,6,7,9,15,16,21,24 \\
5,9,20,22,23 \\
1,2,3,4,6,7,9,15,16,21,24 \\
2,5,6,7,9,16,21,24 \\
9,20 \\
6,17 \\
1,2,4,5,6,7,16,17,21,24 \\
1,2,3,4,5,6,7,9,15,16,17,21,24 \\
1,5,9,20\end{array}$ & $\begin{array}{l}\text { L4,(G14),(G20),(G24) } \\
\text { L6,(L7) } \\
\text { G1 } \\
\text { L3 } \\
\text { L5,L6,(L16) } \\
\text { (G1),(G14) } \\
\text { L6,(G24) } \\
\text { (G3),L6 } \\
\text { L6, } \\
\text { (L1),L5,L20,(G24) }\end{array}$ \\
\hline
\end{tabular}

* The variations are represented by lysate numbers concerned with loss, L, or gain, $\mathrm{G}$, of a strong inhibition reaction graded ++ or + . The loss or gain of a weak reaction is indicated by the use of brackets. 
For those from the remaining nine patients it appeared that a type as defined by one method could be divided into two types by the other. On two occasions the passive procedure gave a greater degree of division.

\section{Application of pyocine-typing methods in epidemiological investigations}

Both typing techniques were used to detect cross-infection when there appeared to be an undue frequency of isolation of $P$. aeruginosa from patients in a ward or clinic. Ward procedures were examined simultaneously for evidence of any breakdown in aseptic routine that might provide a source of infection or lead to transmission. Any such lapse was considered significant if correction was followed by failure to obtain further isolates. Table $\mathrm{V}$ gives details of episodes A-F in which there was good correlation between both typing methods. Episodes G-I, in which there were discrepancies between the two methods, are recorded in table VI.

Episode A. P. aeruginosa was isolated from a patient with meningitis after epidural irrigation with local anaesthetic for a prolapsed disk. Isolates from two other patients seemed to be related and typing confirmed the relationship. Although no common source of infection was found the hazards of the irrigation technique were pointed out to the surgeon and it was abandoned. No further infections occurred in this ward.

Episode $B$. This occurred in an intensive care unit. The isolation of a clearly-defined epidemic strain from the hands of attendant staff indicated a low standard of hand washing. Routine hand disinfection with " Hibiscrub". containing $20 \% \mathrm{v} / \mathrm{v}$ Hibitane (chlorhexidine gluconate solution B.P.) (I.C.I.) was introduced and there were no further isolations of the epidemic strain.

Episode C. The epidemic strain was isolated from four patients. This outbreak was associated with a ventilator that was not adequately disinfected between patients. After the procedure was modified appropriately, no further cases occurred.

Episode D. One ventilator had been used, without the normal cleaning and disinfection, on five patients, as a result of a temporary change of staff. No further case of pseudomonas respiratory-tract infection occurred after the normal procedure had been restored. There was not an absolute correlation between the results of both typing methods, though patterns in respect of the isolates from sputum samples and the ventilator were in good agreement.

Episode $E$ was an outbreak involving infections of wounds and respiratory and urinary tracts with $P$. aeruginosa. Neither a common source nor the mode of transmission was found. The outbreak was discussed with the surgeons and a consequent improvement in the standards of hygiene may have resulted. There were no further isolations of the epidemic strain.

Episode $F$ occurred during and immediately after episode $G$ in the same ward. There had been a number of lapses in aseptic technique (vide infra). The epidemic strain was isolated from a solution of the formulated phenolic disinfectant "Hycolin" (William Pearson, Yorkshire) that was used to treat urine bottles. The disinfectant was being used at the wrong dilution and two 


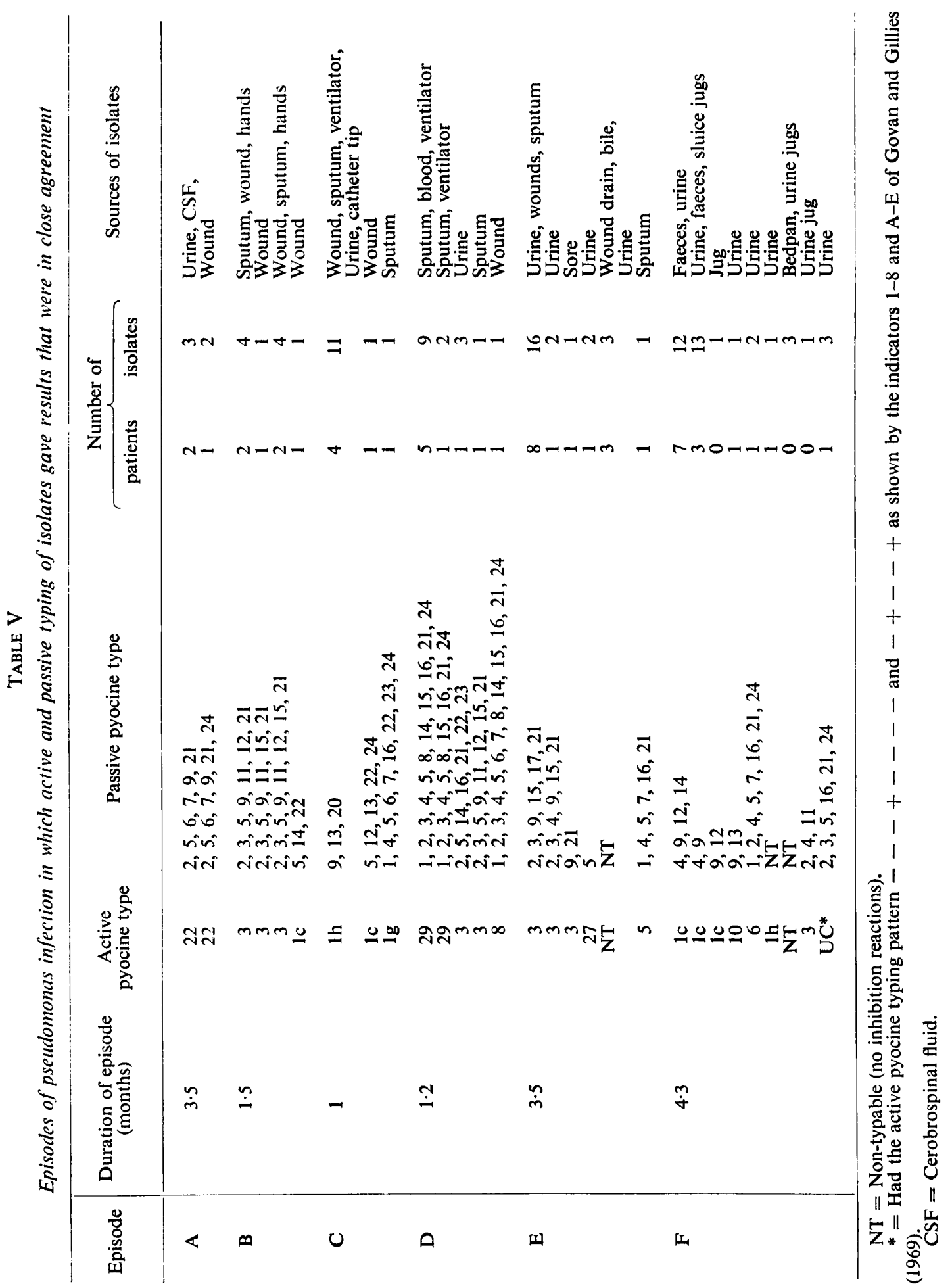




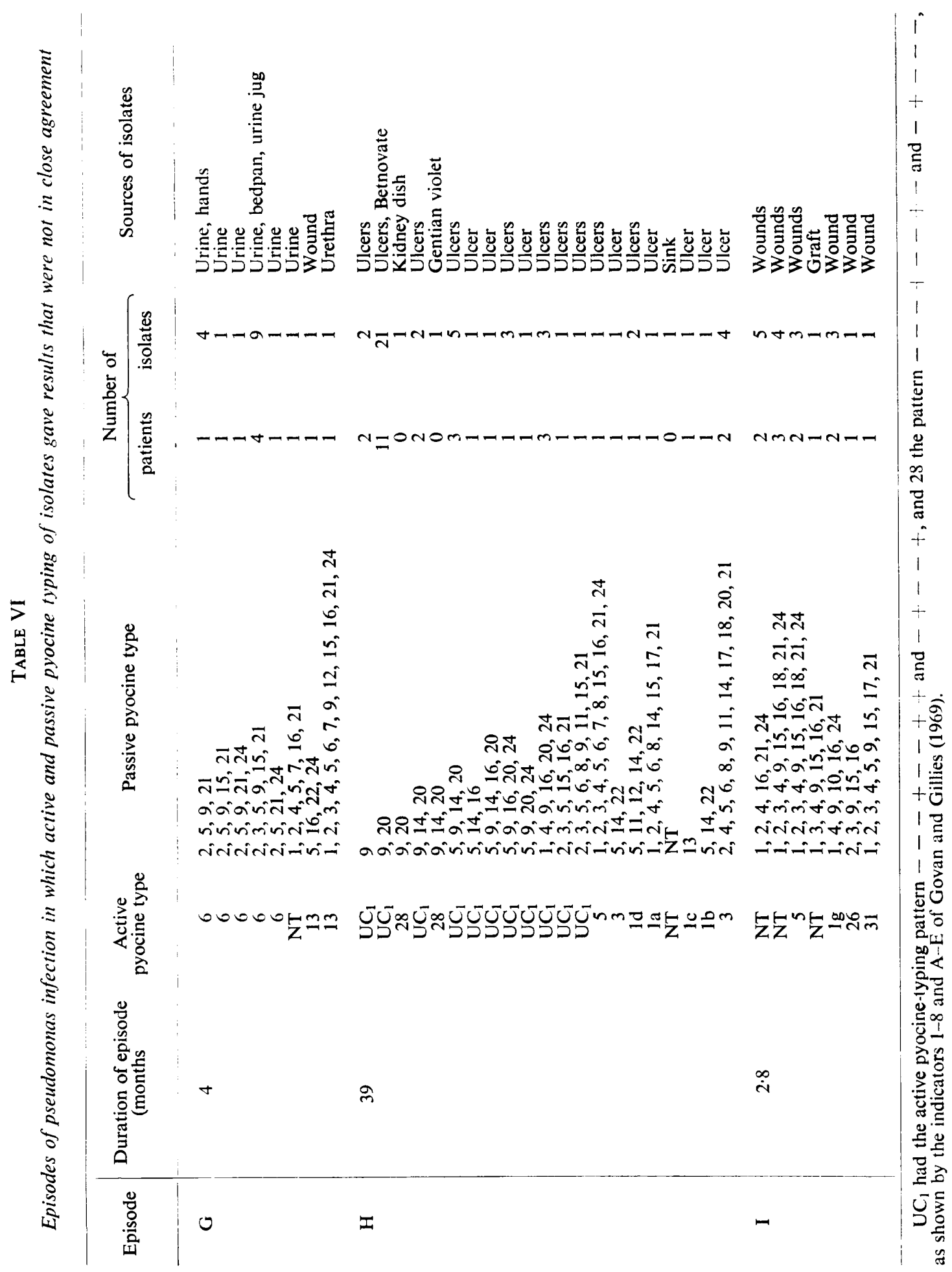


members of the staff were found to be faecal carriers of the epidemic type. After urine collection techniques and standards of hygiene had been improved, no further isolates were obtained. There was good, but not absolute, correlation between the results of the two typing methods.

Episode $G$ occurred in the surgical ward of a genito-urinary unit. The epidemic strain was resistant to gentamicin, tobramycin and carbenicillin. Potential contributory factors included the following: urine bottles and bedpans were treated with a disinfectant that was too dilute and the epidemic strain was isolated from them and from the faeces and hands of a nurse; a closed system of urine drainage was not in use. After the introduction of corrective measures there were no further isolations of the strain.

Although isolates with the characteristic antibiotic resistance pattern were all active pyocine-type 6 , the passive pyocine-typing results did not indicate that all were related.

Episode $H$ was an extensive outbreak in a varicose ulcers clinic, where working conditions were cramped and hygienic standards difficult to maintain. The ulcers were treated with gentian violet. $P$. aeruginosa was isolated from this solution, from the paint brush with which it was applied and from a tube of betamethazone $0.1 \%$ with chlortetracycline $3 \%$ (Betnovate A, Glaxo). Each method of typing indicated that many of the cultures were related.

Episode $I$ was an outbreak of post-operative wound infection in a surgical ward. No source of infection was found, but after revision of aseptic techniques in the ward no further isolations were made. Neither method of typing provided more than an indication that some of the isolates were related.

\section{Discussion}

This study was carried out mainly to evaluate the pyocine sensitivity or " passive" method of typing $P$. aeruginosa. The typing results were compared with those obtained by the " active" method of typing. Both techniques were simple and cheap, though the passive method required the use of a phage applicator. Complications in the interpretation of results obtained by both methods arose out of strain-to-strain variations in the intensity of inhibition reactions. The value of the active method was somewhat restricted by the predominance of certain types. Like Govan and Gillies (1969) and Bergan (1973), we found that types 1 and 3 were the most common. Subdivision of type 1 by a second set of indicators was therefore of value. The passive method was more rapid than the active, but sometimes the strains were difficult to type and reproducibility was poor; the method was usually capable of defining the epidemic strains.

The reliability and reproducibility experiments revealed a degree of variation in inhibition by certain lysates, notably lysate 6 . Such variations may affect the interpretation of results when a reaction with one of these lysates is needed to distinguish between cultures. The use of control strains did not overcome the difficulties though the importance in passive typing of including the set of control strains was indicated by the gradual loss of potency of some lysates. 
The assay procedure that was used to assess potency over 18 months is too time-consuming to be used in the routine assessment of lysates. Further, use of only the most sensitive indicator strains precludes the assessment of consistency of patterns of inhibition. Thus it is unlikely that all the pyocines in any one preparation are assayed. Inclusion of the highly sensitive strains as controls with each typing batch led to a better assessment of the activity of the lysates under conditions of routine use; against a range of indicator strains, decline in the activity of different pyocines in the lysates is more readily observed. Replacement of some lysates in the set is under consideration.

Both methods were applied to nine episodes (A-I) of pseudomonas infection and it was apparent that the results fell into two categories. For episodes A-F the results obtained by both typing techniques were in good agreement, but interpretation of the results in outbreaks $\mathrm{G}, \mathrm{H}$ and $\mathrm{I}$ was less clear.

In episode $G$, the cultures that were resistant to gentamicin, tobramycin and carbenicillin had the same colonial morphology. The colonies were small, dome-shaped and gelatinous, thus differing from any we had seen previously and from the recognised types (Phillips, 1969). All were clearly shown by active typing to be type 6 . Passive typing showed at least two types, although the unusual antibiotic sensitivity, colonial morphology and active typing results suggested that we were dealing with a single strain.

In episode $H$, the active method showed two types. The unclassifiable reactions were distinctive and peculiar to this study. We agree with Merrikin and Terry (1972) that the appearance of a rare type may be of distinct value in epidemiological studies. However, the two types in episode $\mathrm{H}$ were separated by only a single difference in the reactions. Chadwick (1972) argued that when this occurs in the scheme of Gillies and Govan (1966), as for example between types 1 and 10, the cultures form a single group. Possibly the two active types encountered in this episode form a homogeneous group. Passive typing revealed a variety of types and there was poor agreement between the two typing methods. Merrikin and Terry (1972) suggested that the use of stable pyocines in a passive typing system over an extended period might be preferable to the use of an active system depending on variable pyocine production with consequent alteration in type. In the $\mathrm{H}$ outbreak, the isolation of some strains with identical typing patterns at intervals of several years indicated stability of type. Over the same period, the minor variations from the original shown by other strains suggested a degree of instability.

In episode I, the active type 5 was defined by a single reaction. With the second set of indicator strains, normally reserved for the subdivision of type 1 , a consistent reaction was found with indicator $D$ that was inhibited both by type 5 and the untypable cultures. This may indicate that these cultures are indistinguishable. None of the untypable strains we have encountered gave this typing pattern with the second set of indicators, except one isolate obtained in a different hospital 2 years previously. Passive typing showed that cultures were of three types. Two cultures isolated from a single patient at an interval of 3 years differed in that the second gave one active-typing reaction less than the first (type 5) and as a result was untypable; loss of three reactions occurred 
in respect of passive typing and this may indicate that such reactions are less stable than those associated with active typing.

Our prospective study forms the only report of epidemiological studies by means of passive typing except for that of Rampling et al. (1975). Their study was based on active and passive typing and a combination of serology and phage typing. Eleven foci of infection were investigated and a 73.3\% agreement between active and passive pyocine typing was found. The present study showed that although there was good agreement between active and passive methods in six of nine episodes, this was not so in the other three; in one of these the active method seemed to yield the more valuable epidemiological information.

\section{SUMMARY}

An investigation was carried out to determine the value of active and passive pyocine typing in the study of Pseudomonas aeruginosa infections acquired in hospital. Active typing was a more reliable and reproducible method than passive typing. Both methods were used in studies of nine outbreaks of infection. In six of these episodes there was good agreement between the two methods. Less clear-cut results were achieved in the remaining three episodes. In one of these, active typing gave more valuable information. However, both methods are easy, convenient and of value in epidemiological studies.

The authors wish to thank Dr A. Rampling for expert technical advice, Dr M. T. Parker and Professor J. P. Arbuthnott for help and guidance, Mr A. Ogilvie for photography, and Miss Gillian Johnston for preparing the manuscript. The work was supported by grants from the Laboratory Medicine Development Fund, Trinity College, Dublin.

\section{REFERENCES}

Al-dujalli, A. H. AND Harris, D. M. 1974. Evaluation of commercially available antisera for serotyping of Pseudomonas aeruginosa. J. clin. Path., 27, 569.

Al-dujaili, A. H. AND Harris, D. M. 1975. Pseudomonas aeruginosa infection in hospital: a comparison between "infective" and "environmental" strains. J. Hyg., Camb., 75, 195.

Bergan, T. 1973. Epidemiological markers for Pseudomonas aeruginosa. 1. Serogrouping, pyocine typing-and their interrelations. Acta. path. microbiol scand., Section B, 81, 70.

Blair, J. E. and Williams, R. E. O. 1961. Phage typing of staphylococci. Bull. Wld Hlth Org., 24, 771.

ChadwICK, P. 1972. The significance of pattern variations in pyocine typing of Pseudomonas aeruginosa. Can. J. Microbiol., 18, 1153.

EyKYn, S. AND PhILlIPS, I. 1975. Gentamicin-resistant Pseudomonas aeruginosa. Lancet, 1, 861.

FARMER, J. J. 1972. Simplified method of producing pyocins from Pseudomonas aeruginosa. Abstr. Ann. Meeting Am. Soc. Microbiol., M 261, 123.

Farmer, J. J. AND Herman, L. G. 1969. Epidemiological finger printing of Pseudomonas aeruginosa by the production of and sensitivity to pyocin and bacteriophage. Appl. Microbiol., 18, 760.

Gillies, R. R. and Govan, J. R. W. 1966. Typing of Pseudomonas pyocyanea by pyocine production. J. Path. Bact., $91,339$.

Govan, J. R. W. AND Gillies, R. R. 1969. Further studies in the pyocine typing of Pseudomonas pyocyanea. J. med. Microbiol., 2, 17. 
Henderson, A., Maclaurin, J. and Scott, J. M. 1969. Pseudomonas in a Glasgow baby unit. Lancet, $2,316$.

JACOBY, G. A. 1974. Properties of an R plasmid in Pseudomonas aeruginosa producing amikacin (BB-K8), butirosin, kanamycin, tobramycin, and sisomicin resistance. Antimicrob. Agents Chemother., 6, 807.

Kominos, S. D., Copeland, C. E. AND Grosiak, B. 1972. Mode of transmission of Pseudomonas aeruginosa in a burn unit and an intensive care unit in a general hospital. Appl. Microbiol., 23, 309.

Korfhagen, T. R., Loper, J. C. AND Ferrel, J. A. 1975. Pseudomonas aeruginosa R factors determining gentamicin plus carbenicillin resistance from patients with urinary tract colonizations. Antimicrob. Agents Chemother., 7, 64.

Liljedahl, S-O., Malmborg, A-S., Nyström, B. AND SJöberg, L. 1972. Spread of Pseudomonas aeruginosa in a burns unit. J. med. Microbiol., 5, 473.

Lovrexovich, L., Lovrekovich, H. AND JeNKINS, D. C. 1972. Use of ultraviolet light in the typing of Pseudomonas aeruginosa strains by pyocin production. J. clin. Path., 25, 94.

MERrIKIN, D. J. AND TerRY, C. S. 1972. Variability of pyocine type and pyocine sensitivity in some strains of Pseudomonas aeruginosa. J. appl. Bact., 35, 667.

Osman, M. A. M. 1965. Pyocine typing of Pseudomonas aeruginosa. J. clin. Path., 18, 200.

PARKER, M. T. 1972. Characterisation and typing of Pseudomonas aeruginosa. J. gen. Microbiol., 73, vi.

Paterson, A. C. 1965. Bacteriocinogeny and lysogeny in the genus Pseudomonas. J. gen. Microbiol., 39, 295.

PHILLIPS, I. 1969. Identification of Pseudomonas aeruginosa in the clinical laboratory. $J$. med. Microbiol., $2,9$.

RAmpling, A. AND WHitBy, J. L. 1972. Preparation of phage-free pyocin extracts for use in the typing of Pseudomonas aeruginosa. J. med. Microbiol., 5, 305.

Rampling, A., Whitby, J. L. AND WiLdy, P. 1975. Pyocin-sensitivity testing as a method of typing Pseudomonas aeruginosa: use of "phage-free" preparations of pyocin. J. med. Microbiol., 8, 531.

TAGG, J. R. AND MUSHIN, R. 1971. Epidemiology of Pseudomonas aeruginosa infection in hospitals. 1. Pyocine typing of Ps. aeruginosa. Med. J. Aust., 1, 847.

Thomas, E. T., Jones, L. F., Simao, E., Sole-Vernin, C. And Farmer, J. J. 1975. Epidemiology of Pseudomonas aeruginosa in a general hospital: a four year study. J. clin. Microbiol., 2, 397.

Tinne, J. E., Gordon, A. M., Bain, W. H. and Mackey, W. A. 1967. Cross-infection by Pseudomonas aeruginosa as a hazard of intensive surgery. Br. med. J., 4, 313.

Tripathy, G. S. AND Chadwick, P. 1971. The effect of mitomycin C on the pyocine typing patterns of hospital strains of Pseudomonas aeruginosa. Can. J. Microbiol., 17, 829. 